\title{
PRACTICAL AND COMPREHENSIVE GUIDELINES FOR BEDSIDE CEREBRAL HEMOMETABOLIC MULTITHERAPEUTIC OPTIMIZATION
}

\author{
Julio Cruz ${ }^{1}$
}

\begin{abstract}
In recent years, noncomprehensive "guidelines" were proposed for the management of severe acute brain injuries, focusing strictly on two approaches: 1) to maintain cerebral perfusion pressure anywhere above $70 \mathrm{~mm} \mathrm{Hg}$; and 2) to maintain arterial carbon dioxide tension levels above 30 torr. Strictly following these propositions, a recently reported prospective controlled study addressed mortality rates of no less than $75-76 \%$, far worse than mortality rates reported before those "guidelines" were published. As a humanitarian alternative, the present comprehensive guidelines are aimed at addressing practical bedside strategies to manage no only intracranial pressure and cerebral perfusion pressure but also cerebral extraction of oxygen, based on solid previously reported papers which revealed the lowest mortality rates (below 15\%) in the pertinent literature, in recent years.
\end{abstract}

KEY WORDS: cerebral extraction of oxygen, intracranial pressure, guidelines, head injury.

\begin{abstract}
Diretrizes práticas e abrangentes para otimização hemometabólica cerebral multiterapêutica
RESUMO - Em anos recentes, "diretrizes" não abrangentes foram propostas para o tratamento de traumatismos cerebrais agudos graves, enfocando estritamente em duas abordagens: 1) manter-se a pressão de perfusão cerebral em quaisquer níveis acima de $70 \mathrm{~mm} \mathrm{Hg}$; e 2) manter-se a pressão parcial de gás carbônico arterial acima de 30 torr. Seguindo estritamente tais proposições, artigo recentemente publicado envolvendo estudo prospectivo controlado revelou taxas de mortalidade de não menos que $75-76 \%$, muitissímo piores do que taxas de mortalidade publicadas anteriormente a essas "diretrizes". Como uma alternativa humanitária, as diretrizes aqui propostas têm como meta explicar estrategias para que se tratem não apenas a pressão intracraniana e a pressão de perfusão cerebral, mas também a extração cerebral de oxigênio, baseando-se em trabalhos sólidos publicados anteriormente, os quais revelaram as menores taxas de mortalidade (inferiores a $15 \%)$ da literatura pertinente, em anos recentes.
\end{abstract}

PALAVRAS-CHAVE: extração cerebral de oxigênio, pressão intracraniana, diretrizes, traumatismo cerebral.

Back in 1996, "guidelines" for the management of severe acute brain injuries were published by several authors and were said to be "evidence-based"1. This was not true, however, because no less than four strictly relevant previously published papers $^{2-5}$ were omitted from citation and discussion in those "guidelines", despite the fact that those four papers had been published in leading international medical journals. Therefore, those "guidelines"1 were biased and not truly evidence-based, as would have been required in a publication of that kind.

Strictly following those 1996 "guidelines"1, a recently published prospective controlled study ${ }^{6}$ focusing on the use of induced hypothermia addressed mortality rates of no less than $75-76 \%$, far worse than low mortality rates ${ }^{2-4}$ reported before the aforementioned 1996 "guidelines" were published. In this recent study ${ }^{6}$, routine attempts were made to avoid hyperventilation therapy, maintaining arterial carbon dioxide tension $\left(\mathrm{PCO}_{2}\right)$ levels above 30 torr and cerebral perfusion pressure (CPP) anywhere above $70 \mathrm{~mm}$ $\mathrm{Hg}$, in addition to frequent mannitol administration and barbiturate therapy for all patients, supplemented by induced hypothermia for the study group.

As a humanitarian alternative to those 1996 "guidelines"1, the present practical and comprehensive guidelines address not only treatment of intracranial pressure (ICP) and CPP but also cerebral ex-

\footnotetext{
${ }^{1}$ M.D., Ph.D., Director, The Comprehensive International Center for Neuroemergencies and Postgraduate Professor, Escola Paulista de Medicina, Federal University of Sao Paulo, Sao Paulo SP, Brazil.
}

Received 11 February 2002. Accepted 27 March 2002.

Dr. Julio Cruz - CICNEM - P.O. Box Cx. Postal 57011 - 04093-970 São Paulo SP - Brasil. FAX: 551155764092 
traction of oxygen $\left(\mathrm{CEO}_{2}\right)^{2,4,7-12}$. The latter represents the ratio of global cerebral consumption of oxygen $\left(\mathrm{CCO}_{2}\right)$ to cerebral blood flow $(\mathrm{CBF})^{8}$, and thus provides accurate bedside information regarding coupling or uncoupling between $\mathrm{CBF}$ and $\mathrm{CCO}_{2}$. Adequate $\mathrm{CBF}-\mathrm{CCO}_{2}$ coupling, in turn, has already been reported in association with significantly better longterm clinical outcomes from severe acute brain injuries than when a flow-metabolism uncoupling exists during the acute phase of illness ${ }^{9,13}$.

Of these two latter studies, the first was based on purely observational (noninterventional) clinical research ${ }^{13}$, whereas the second addressed a large prospective controlled trial involving 353 adult patients ${ }^{9}$. In the latter series, patients were selected for having predominantly diffuse brain swelling and early intracranial hypertension for both groups, and the use of optimized hyperventilation was conclusively confirmed in association with significantly better long-term clinical outcomes than in the control group, where CPP was managed alone (without the use of optimized hyperventilation therapy $)^{9}$.

\section{ICP and CPP}

A frequently neglected feature in the management of acute brain injuries is that normal ICP is approximately 5 and $10 \mathrm{~mm} \mathrm{Hg}$ only for children and adults, respectively. Therefore, the present guidelines propose that elevated ICP levels be aggressively treated so that they are maintained below 15 and $20 \mathrm{~mm} \mathrm{Hg}$ for children and adults, respectively. Additionally, instead of maintaining CPP anywhere above a certain level, the present guidelines propose maintaining CPP in the approximate ranges of 5080 and $60-95 \mathrm{~mm} \mathrm{Hg}$ for children and adults, respectively.

Indeed, normal-to-increased CPP (the difference between mean arterial pressure and mean ICP) has been clearly shown to totally lack any correlation with $\mathrm{CBF}$, oxygen extraction, and oxygen consumption in severe acute brain injuries ${ }^{5}$. This recently reported, striking finding therefore strongly indicated that maintaining high CPP levels leads to absolutely no clinical benefit, insofar as physiological optimization is concerned, based on mistaken therapies that iatrogenically increase the blood pressure. Furthermore, as early as 1968 , it has been well demonstrated experimentally that arterial hypertension does worsen traumatic brain swelling ${ }^{14}$. This original animal study thus suggested that artificially maintaining high CPP levels (as proposed in the 1996 "guidelines"1) may, in fact, lead to catastrophic consequen- ces when managing brain-injured patients with decreased cerebrospinal fluid spaces and elevated ICP.

\section{$\mathrm{CEO}_{2}, \mathrm{CCO}_{2}$, and $\mathrm{CBF}$}

$\mathrm{CEO}_{2}$ is simply the arteriojugular oxyhemoglobin saturation difference, and represents one of several novel parameters that we have previously proposed for bedside assessment of cerebral hemometabolism ${ }^{2,4,7-12}$. Because $\mathrm{CEO}_{2}$ is the ratio of $\mathrm{CCO}_{2}$ to $\mathrm{CBF}$, it then becames clear that $\mathrm{CCO}_{2}$ and $\mathrm{CBF}$ need not be measured, because $\mathrm{CEO}_{2}$ alone accurately informs about coupling or uncoupling between CBF and $\mathrm{CCO}_{2}^{8,9}$.

The normal $\mathrm{CEO}_{2}$ ranges are $17-35 \%$ and $24-42 \%$ for children and adults, respectively ${ }^{2,4,8-12}$. For therapeutic purposes, the target values are the normal means of $26 \%$ and $33 \%$, respectively. These ranges should be used for therapeutic maintenance (besides maintaining the aforementioned ranges for ICP and (PP), whenever possible. Normal-to-increased $\mathrm{CEO}_{2}$ values are indicative of relative cerebral hypoperfusion, where $\mathrm{CBF}$ is reduced relative to $\mathrm{CCO}_{2}$. Under these circumstances, attempts should be made to increase $\mathrm{CBF}$ and decrease $\mathrm{CEO}_{2}$, however without compromising adequate ICP control. Conversely, normal-to-decreased $\mathrm{CEO}_{2}$ values are indicative of relative cerebral hyperperfusion, where $\mathrm{CBF}$ is high relative to $\mathrm{CCO}_{2}$. Under these circumstances, if ICP is mildly or more markedly elevated, attempts should be made to decrease $\mathrm{CBF}$ and increase $\mathrm{CEO}_{2}$, ideally without exceeding the upper normal $\mathrm{CEO}_{2}$ limit.

\section{Optimized nonbarbiturate sedation}

This is the first step for cerebral hemometabolic optimization, which also allows for adequate mechanical ventilation. In recent years, midazolam has been the most frequently used drug, sometimes in combination with fentanyl for concomitant analgesia. The effects of both drugs on $\mathrm{CEO}_{2}$ are not yet known, but their use can be titrated to maintain normal ICP, $\mathrm{CPP}$, and $\mathrm{CEO}_{2}$ as well. The main side effect of this treatment modality is arterial hypotension, which can be reversed by decreasing the administered doses. Expectedly, $\mathrm{CEO}_{2}$ could increase if arterial hypotension decreases $\mathrm{CBF}$ relative to $\mathrm{CCO}_{2}$. Conversely, $\mathrm{CEO}_{2}$ could also remain normal, because sedation may decrease $\mathrm{CCO}_{2}$ as well. Therefore, directly measuring $\mathrm{CEO}_{2}$ is the best way of evaluating potential side effects or benefits of nonbarbiturate intravenous sedation. 


\section{Optimized mannitol}

Because we also monitor $\mathrm{CEO}_{2}$ (instead of ICP and CPP alone), it then became possible to define an optimal use of intravenous mannitol. This is because, based on ICP alone, the repetitive use of mannitol may lead to hyperosmolality, hypovolemia, and even acute renal failure in extreme cases. Indeed, we have previously reported that the best indication for mannitol is when elevated ICP is associated with normal-to-increased $\mathrm{CEO}_{2}$ (relative cerebral hypoperfusion) ${ }^{7}$. Under these conditions, fast intravenous mannitol not only lowers elevated ICP but also decreases the $\mathrm{CEO}_{2}$ toward normal levels, indicative of adequate therapeutic restoration of global $\mathrm{CBF}-\mathrm{CCO}_{2}$ coupling ${ }^{7}$. These positive effects are because, as previously reported ${ }^{15}, \mathrm{CBF}$ does increase following mannitol administration.

The use of nonoptimized mannitol (with normalto-decreased $\mathrm{CEO}_{2}$, or relative cerebral hyperperfusion) may also be adopted, but only as long as a sustained benefit regarding ICP control can be confirmed. Nonoptimized mannitol administration should be discontinued if its effect on ICP control lasts less than two hours. The usual mannitol dose for fast intravenous infusion is in the range of 0.4$0.7 \mathrm{~g} / \mathrm{kg}$, but higher doses could also be considered, especially in the event that abnormal pupillary widening is found, and/or in preparation for decompressive surgery (see later).

\section{Optimized hyperventilation}

Also because we monitor $\mathrm{CEO}_{2}$ (instead of ICP and (PP alone), it was possible to first propose the use of optimized hyperventilation. The latter is indicated in an opposite fashion to that of optimized mannitol; that is, optimized hyperventilation is used for elevated ICP and normal-to-decreased $\mathrm{CEO}_{2}$, or relative cerebral hyperperfusion ${ }^{2,4,9-12}$. As a general rule, optimized hyperventilation is instituted with arterial (or expired) $\mathrm{PCO}_{2}$ levels in the approximate range of 20-30 torr, and is implemented for variable periods of no less than 3-4 days. Some patients with more challenging ICP problems will require optimized hyperventilation for longer periods.

According to these standards, when normal ICP levels are achieved, and after at least 4-5 days, $\mathrm{PCO}_{2}$ values of 30 torr or slightly higher should be gradually restored by slowly reversing the process of optimized hyperventilation, but only as long as normal ICP levels are maintained. In our experience, ICP, CPP, and $\mathrm{CEO}_{2}$ monitoring and management have lasted appro- ximately 7-10 days for both adults $2,4,9,11$ and children $^{12}$, according to our comprehensive treatment protocol. This is in sharp contrast to approximately $18+13$ days reported by those who did not hyperventilate the patients, and iatrogenically induced CPP values anywhere above $70 \mathrm{~mm} \mathrm{Hg}^{16}$.

\section{Optimized barbiturate therapy}

Also based on $\mathrm{CEO}_{2}$ and jugular oxyhemoglobin saturation $\left(\mathrm{SjO}_{2}\right)$ monitoring, we ${ }^{17}$ first demonstrated that, immediately following intravenous bolus injections of barbiturates for the treatment of elevated ICP refractory to ongoing optimized mannitol and optimized hyperventilation, blood pressure may fall, along with $\mathrm{SjO}_{2}$ decreases ( $\mathrm{CEO}_{2}$ increases) in some patients. Therefore, caution should be exercised whenever intravenous barbiturate boluses are administered for ICP control, and the use of vasopressor drugs should be immediately instituted if necessary.

The usual barbiturate dose (pentobarbital or thiopental) is approximately $15 \mathrm{mg} / \mathrm{kg}$ for the loading dose over $60-90$ minutes, followed by approximately $1.5-2 \mathrm{mg} / \mathrm{kg} / \mathrm{hour}$ for the maintenance dose. With normal and stable ICP levels for at least 24 hours, the cumulative use of optimized mannitol, optimized hyperventilation, and optimized barbiturate therapy can then be gradually discontinued in the reverse order of implementation, starting with barbiturate discontinuation. The latter is usually accomplished by decreasing the infusion dose by $50 \%$ at intervals of approximately 6 hours. Discontinuing the cumulative treatment protocol ${ }^{9-12}$ should be considered no earlier than at least 4-5 days after the start of treatment. When instituting barbiturate therapy if necessary, it is obvious that the first step of the protocol (nonbarbiturate intravenous sedation) should be discontinued.

\section{Decompressive surgery}

Having optimized and maximized the above-described nonsurgical cumulative treatment protocol, as gradually or rapidly as required by less or more challenging ICP problems, decompressive surgery should then be considered for refractory intracranial hypertension (ideally before ICP exceeds $30 \mathrm{~mm}$ $\mathrm{Hg}$ ). The choice of external versus internal decompression depends on the presence or absence of brain areas that are presumably unviable (e.g., hemorrhagic contusions), as well as the neurosurgeon's experience. We have successfully adopted decompressive surgery ${ }^{11,12,18,19}$ as the final step in the cu- 
mulative treatment protocol that we developed over the years, and for a large number of patients.

\section{Comparative clinical outcomes}

According to our previously reported treatment protocol, the best mortality rates have ranged from 9\% (for comatose adult patients with predominantly traumatic diffuse brain swelling) ${ }^{9}$ to $14 \%$ (for comatose adult patients with acute subdural hematomas and postoperative brain swelling) ${ }^{11}$. For selected children in acute coma with traumatic intracranial hypertension, our treatment protocol was associated with a mortality rate of $4 \%$ only ${ }^{12}$. These figures are in sharp contrast to $75-76 \%$ mortality rates ${ }^{6}$ reported for adult patients treated according to the abovementioned 1996 "guidelines"1, and strongly indicate that our presently proposed comprehensive guidelines are far more humanitarian and clinically sound than any other previously reported.

\section{Abandoning brain tissue probes}

A recent study ${ }^{20}$ involving sophisticated noninvasive positron emission tomography has definitively ruled out the occurrence of regional brain ischemia following hyperventilation therapy, a finding in full agreement with our previously reported global (arteriojugular) measurements involving both oxygen and

Table 1. Indications for arteriojugular monitoring and management.

1 Severe acute brain trauma with suspected or confirmed intracranial hypertension;

2 Some forms of nontraumatic intracranial hemorrhage with suspected or confirmed intracranial hypertension;

3 Hepatic encephalopathy with suspected or confirmed intracranial hypertension;

4 Uremic encephalopathy with suspected or confirmed intracranial hypertension;

5 Near-drowning with suspected or confirmed intracranial hypertension;

6 Posthypoxic encephalopathy with suspected or confirmed intracranial hypertension;

7 Meningitis or meningoencephalitis with suspected or confirmed intracranial hypertension;

8 Hypertensive encephalopathy (including eclamptic encephalopathy) with suspected or confirmed intracranial hypertension;

9 Septic encephalopathy with suspected or confirmed intracranial hypertension glucose extraction ${ }^{2,4}$. Indeed, we have also recently reported that global brain ischemia is absolutely rare in acute brain trauma, as evaluated by simultaneous arteriojugular oxygen and lactate differences ${ }^{11}$.

Despite the above-mentioned findings, an alternative monitoring "modality" involving acute placement of brain tissue probes to evaluate focal oxygen tension ${ }^{21}$ has claimed that hyperventilation is harmful. In this recent paper ${ }^{21}$, the authors found that even when the jugular catheter showed high cerebral venous oxygenation, hyperventilation dropped the brain tissue oxygen tension to so-called "critically low" levels. In this respect, however, it is well known that acute placement of brain tissue probes causes focal microvascular compression and distortion, besides focal blood-brain barrier disruption (because the probes are too stiff relative to the soft brain tissue).

Therefore, it is not surprising that brain tissue probes will almost invariably show low oxygen values, which are, nevertheless, just focal and artifactual relative to the global brain. The latter is better evaluated by techniques where the brain tissue is not invaded (e.g., jugular measurements or positron emission tomography). Furthermore, because healthy human beings will just never volunteer to have their heads open for any brain tissue probe to be placed, normal physiological values for these probes designed for any "measurement" (e.g., microdialysis, oxygen tension, temperature, etc) are not even known, and most likely will never be known. Therefore, "critical" values for any element measured by these focal brain tissue probes represent speculation and misinformation, at least until otherwise proven.

Because normal physiological values are not even known, and because these focal brain tissue probes are highly invasive, their use can be regarded as gross animal experimentation in humans $\mathrm{s}^{21-23}$, which should therefore be abandoned and eventually punished, rather than being commercially and industrially promoted.

\section{Future prospects}

Because a variety of acute intracranial insults (besides brain trauma) may be frequently associated with combined abnormalities regarding ICP, CPP, and $\mathrm{CEO}_{2}$, Table 1 shows a broad spectrum of acute intracranial disease processes in which our proposed monitoring and protocol could also be explored. It is hoped that this comprehensive, practical, and inexpensive monitoring and treatment protocol will also help lowering mortality rates in acute intracranial events other than acute severe brain trauma. 


\section{REFERENCES}

1. Bullock R, Chesnut RM, Clifton G, et al. Guidelines for the management of severe head injury: Brain Trauma Foundation. J Neurotrauma 1996;13:639-734.

2. Cruz J. Combined continuous monitoring of systemic and cerebral oxygenation in acute brain injury: preliminary observations. Crit Care Med 1993;21:1225-1232.

3. Cruz J, Hoffstad OJ, Jaggi JL. Cerebral lactate-oxygen index in acute brain injury with acute anemia: assessment of false versus true ischemia. Crit Care Med 1994;22:1465-1470.

4. Cruz J. An additional therapeutic effect of adequate hyperventilation in severe acute brain trauma: normalization of cerebral glucose uptake. J Neurosurg 1995;82:379-385.

5. Cruz J, Jaggi JL, Hoffstad OJ. Cerebral blood flow, vascular resistance, and oxygen metabolism in acute brain trauma: redefining the role of cerebral perfusion pressure ? Crit Care Med 1995;23:1412-1417.

6. Polderman KH, Peerdeman SM, Girbes ARJ. Hypophosphatemia and hypomagnesemia induced by cooling in patients with severe head injury. J Neurosurg 2001;94:697-705.

7. Cruz J, Miner ME, Allen SJ, Alves WM, Gennarelli TA. Continuous monitoring of cerebral oxygenation in acute brain injury: injection of mannitol during hyperventilation. J Neurosurg 1990;73:725-730.

8. Cruz J, Jaggi JL, Hoffstad OJ. Cerebral blood flow and oxygen consumption in acute brain injury with acute anemia: an alternative for the cerebral metabolic rate of oxygen consumption? Crit Care Med 1993;21:1218-1224.

9. Cruz J. The first decade of continuous monitoring of jugular bulb oxyhemoglobin saturation: management strategies and clinical outcome. Crit Care Med 1998;26:344-351.

10. Cruz J, Minoja G, Mattioli C, et al. Severe acute brain trauma. In Cruz J (ed). Neurologic and Neurosurgical Emergencies. Philadelphia: W.B. Saunders, 1998:405-436.

11. Cruz J, Minoja G, Okuchi K. Improving clinical outcomes from acute subdural hematomas with the emergency preoperative administration of high doses of mannitol: a randomized trial. Neurosurgery 2001;49:864-871.
12. Cruz J, Nakayama P, Imamura JH, Rosenfeld KGW, de Souza HS, Giorgetti GVF. Cerebral extraction of oxygen and intracranial hypertension in severe, acute, pediatric brain trauma: preliminary novel management strategies. Neurosurgery 2002;50:774-780.

13. Jaggi JL, Obrist WD, Gennarelli TA, Langfitt TW. Relationship of early cerebral blood flow and metabolism to outcome in acute head injury. J Neurosurg 1990;72:176-182.

14. Schutta HS, Kassell NF, Langfitt TW. Brain swelling produced by injury and aggravated by arterial hypertension: a light and electron microscopic study. Brain 1968;91:281-294.

15. Bruce DA, Langfitt TW, Miller JD, et al. Regional cerebral blood flow, intracranial pressure, and brain metabolism in comatose patients. J Neurosurg 1973;38:131-144.

16. Rosner MJ, Rosner SD, Johnson AH. Cerebral perfusion pressure: management protocol and clinical results. J Neurosurg 1995;83:949-962.

17. Cruz J. Adverse effects of pentobarbital on cerebral venous oxygenation of comatose patients with acute traumatic brain swelling: relationship to outcome. J Neurosurg 1996;85:758-761.

18. Cruz J, Gennarelli TA, Alves WM. Continuous monitoring of cerebral oxygenation in acute brain injury: multivariate assessment of severe intracranial "plateau" wave: case report. J Trauma 1992;32:401-403.

19. Cruz J, Zager EL, Sinson GP, Hoffstad OJ. Cerebral extraction of oxygen, lactate production, and perfusion pressure in gunshot wound to the head: case report. J Trauma 1996;40:445-448.

20. Diringer MN, Videen TO, Yundt K, et al. Regional cerebrovascular and metabolic effects of hyperventilation after severe traumatic brain injury. J Neurosurg 2002;96:103-108.

21. Imberti R, Bellinzona G, Langer M. Cerebral tissue $\mathrm{PO}_{2}$ and $\mathrm{SjvO}_{2}$ changes during moderate hyperventilation in patients with severe traumatic brain injury. J Neurosurg 2002;96:97-102.

22. Menzel M, Doppenberg EMR, Zauner A, Soukup J, Reinert MM, Bullock R. Increased inspired oxygen concentration as a factor in improved brain tissue oxygenation and tissue lactate levels after severe human head injury. J Neurosurg 1999;91:1-10.

23. Van den Brink WA, Van Santbrink H, Steyerberg EW, et al. Brain oxygen tension in severe head injury. Neurosurgery 2000;46:868-878. 